\title{
Immunohistochemical localization and functional characterization of somatostatin receptor subtypes in a corticotropin releasing hormone- secreting adrenal phaeochromocytoma: review of the literature and report of a case
}

\author{
R.M. Ruggeri, ${ }^{1}$ F. Ferraù,, ${ }^{1}$ A. Campennì, ${ }^{2}$ A. Simone, ${ }^{3}$ V. Barresi, ${ }^{3}$ G. Giuffrè, ${ }^{3}$ G. Tuccari, ${ }^{3}$ \\ S. Baldari, ${ }^{2}$ F. Trimarchi ${ }^{1}$ \\ ${ }^{1}$ Department of Medicine and Pharmacology, Section of Endocrinology; 'Department of Radiology, \\ Section of Nuclear Medicine; ${ }^{3}$ Department of Pathology, University of Messina, Messina, Italy
}

(C)2009 European Journal of Histochemistry

Somastostatin receptors are frequently expressed in phaeochromocytoma but data on somatostatin receptor subtyping are scanty and the functional response to the somatostatin analogue octretide is still debated. We report an unusual case of pheochromocytoma, causing ectopic Cushing's syndrome due to CRH production by the tumour cells, in a 50 -yr-old woman. Abdominal computed tomography revealed an inhomogeneous, $9-\mathrm{cm}$ mass in the right adrenal gland, and [ ${ }^{11}$ In-DTPA $\left.^{0}\right]$ octreotide scintigraphy showed an abnormal uptake of the radiotracer in the right perirenal region, corresponding to the adrenal mass. The patient underwent laparoscopic surgery and formalin-fixed and paraffinembedded samples were studied. The tumour was extensively characterized by immunohistochemistry and somatostatin receptor (SSTRs) subtypes expression was analyzed. Histological and immunohistochemical examination of the surgical specimens displayed a typical pheochromocytoma, which was found to be immunoreative to S-100, chromogranin A and neurofilaments. Immunostaining for SSTR subtypes showed a positive reaction for $S_{S T R}, S_{2} T_{2 A}, S S T R_{2 B}$, antisera on tumour cells. The intense and diffuse immunostaining for corticotropin releasing hormone (CRH) antiserum indicated that Cushing's disease was dependent on $\mathrm{CRH}$ overproduction by the pheochromocytoma, in which no immunostaining for adrenocorticotropic hormone was found. Our report confirms the heterogeneity of the pattern of SSTR expression in pheochromocytomas, and provide further evidence for functional SSTR subtype SSTR 2 in a subgroup of pheochromocytomas, suggesting that these tumours may represent potential target for octreotide treatment.

Key words: phaeochromocytoma, neuroendocrine tumours, somatostatin receptors, octreotide, corticotropin releasing hormone.

Correspondence: Rosaria M. Ruggeri,

Department of Medicine and Pharmacology,

Section of Endocrinology of University of Messina,

Pad. H, $4^{\circ}$ piano - A.0.U. Policlinico G. Martino,

Via Consolare Valeria 198125 Messina, Italy

Tel.: +39.090.2213840.

Fax: +39.090.2213518.

E-mail: rmruggeri@unime.it

Paper accepted on November 4, 2008

European Journal of Histochemistry

2009; vol. 53 issue 1 (January-March): 1-6

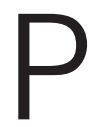

haeochromocytomas are tumours derived from the chromaffin cells of the sympathoadrenal system, generally associated with cathecolamine overproduction. They represent a rare condition, occurring in less than $0.2 \%$ of patients with hypertension. The diagnosis of sporadic phaeochromocytoma is based on clinical history and features characterized by the triad episodic headache, sweating, and tachycardia, but an increasing number of these tumours are diagnosed in patients without classical symptoms (Pacak et al., 2001). Ectopic Cushing's syndrome is one of the possible, albeit unusual, expression of pheochromocytoma. Up to date, there are few reports of pheochromocytomas producing adrenocorticotropic hormone (ACTH) and/or ACTH precursors (O'Brien T et al., 1992; Chen et al., 1995; White et al., 2000), and even more limited is the number of cases in which pheochromocytoma secrete corticotropin releasing hormone $(\mathrm{CRH})$ (Eng et al., 1999; Bayraktar et al., 2006).

Similar to other neuroendocrine tumours, pheochromocytomas often express somatostatin receptors (SSTR) (De Herder and Hofland, 2004), but data on the specific SSTRs subtypes expressed within the tumours are thus far sparse and conflicting and the real therapeutic effectiveness of somatostatin analogue in these tumours is still debated (Reubi et al., 1992; Kubota et al., 1994; Epelbaum et al., 1995; Hofland et al., 1999; Mundschenk et al., 2003; Unger et al., 2004; Ueberberg et al., 2005; Unger et al., 2007).

\section{Materials and Methods}

\section{Patient}

A 50-year-old woman referred to our Endocrine Unit for help in the management of severe 
hypokalaemia and hypertension. At the time of presentation, she displayed typical Cushing's features. Plasma ACTH and serum cortisol levels were elevated (73 pmol/L, n.v. 2-11, and 3773 nmol/L, n.v. 215-1000, respectively), without circadian rhythm (midnight cortisol $2905 \mathrm{nmol} / \mathrm{L}$ ). Mean 24-h urinary free cortisol excretion (UFC) was markedly elevated (1627 nmol/24h; n.v. 206744), while plasma and urinary ephinefrine, normetanephrine and metanephrine concentrations were within the normal range. Serum chromogranin A levels were markedly increased (1060 $\mathrm{ng} / \mathrm{mL}$; n.v. <100). Abdominal computed tomography $(C T)$ demonstrated a $9 \mathrm{~cm}$ round mass with calcifications and central necrosis in the right adrenal gland. No other abnormalities were detected either by CT of neck and chest or by magnetic resonance imaging of the pituitary. A whole-body scintigraphy (WBS) with ${ }^{[111}$ InDTPA $^{\circ}$ ] octreotide $\left(\right.$ Octreoscan $\left.{ }^{\circledR}\right)$ showed abnormal uptake in the area corresponding to the adrenal mass demonstrated by CT (Figure 1), indicating expression of the SSTRs by the tumour cells. Thus, medical treatment with the somatostatin analog octreotide ( $0.1 \mathrm{mg}$ s.c. two times daily) was started. This treatment induced a dramatic improvement in clinical signs and symptoms, which was accompanied by rapid normalization of plasma ACTH, serum cortisol and UFC levels, serum potassium and glucose levels. When her clinical condition improved, the patient underwent surgery. The post-operative course was uncomplicated, and hydrocortisone replacement therapy was not necessary. Clinical features of Cushing's syndrome gradually disappeared of all and at the last follow-up, three years after surgery, the patient is free of disease.

\section{Histological and immunohistochemical evaluation}

The neoplastic surgical sample was fixed in $10 \%$ neutral formalin for 24 hours at room temperature; successively, some representative specimens were embedded in paraffin at $55^{\circ} \mathrm{C}$ and cut into $5 \mu \mathrm{m}$ thick consecutive sections to perform Haematoxylin-Eosin (H\&E) routine histological stain and immunohistochemical procedures. The local Ethics Committee approved the experimental protocol and an informed consent was obtained from the patient.

The immunohistochemical characterization of the tumour was performed utilizing, separately,

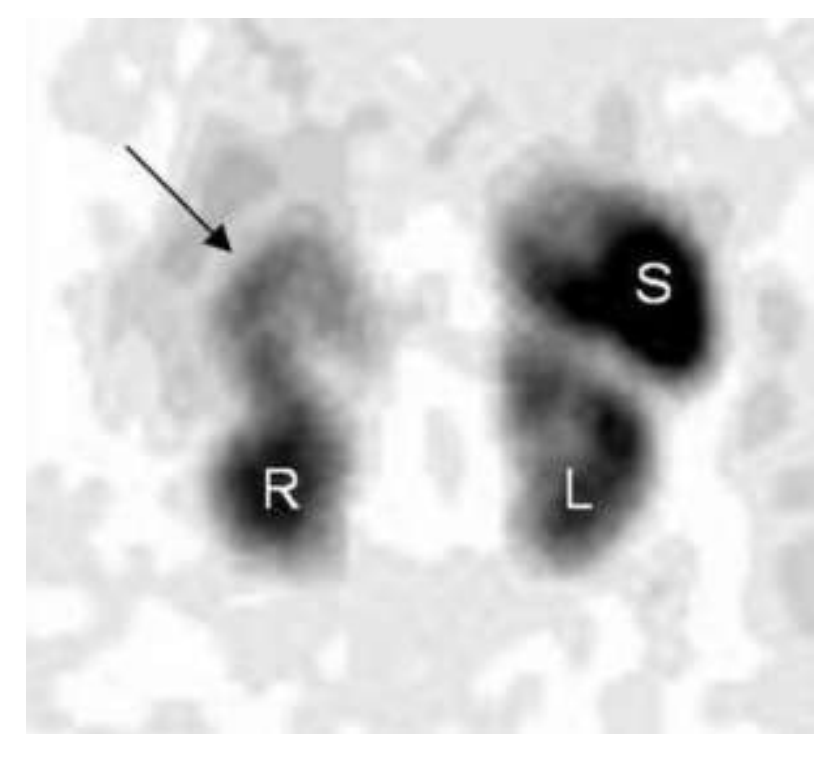

Figure 1. Coronal plane of the whole-body scintigraphy, performed 4 hours after injection of [ ${ }^{111}$ In-DTPA $\left.{ }^{0}\right]$ octreotide, shows abnormal uptake in the area corresponding to the adrenal mass demonstrated by CT (black arrow) and the normal uptake of right (R) and left (L) kidneys and of spleen (S).

the following antisera: a) monoclonal antisera against chromogranin A (working diluition $1: 100$ ), neurofilaments (wd 1:100), human Ki-67 antigen (clone MIB-1, wd 1:200) and ACTH (wd) 1:75), (all from DAK0, Carpinteria, CA, USA); b) polyclonal antisera against S-100 (DAK0, wd 1:300), CRH, and Pro-opiomelanocortin Precursor (POMC) (all from Abcam, Cambridge, UK, wd 1:100).

Antigen retrieval procedures (microwave oven exposure for 3 cycles $\times 5$ min at $100^{\circ} \mathrm{C}$, in $10 \mathrm{mM}$ citrate buffer, $\mathrm{pH}$ 6.0) were carried out for the antisera against ACTH, chromogranin $A$ and human $\mathrm{Ki}-67$ antigen. A pre-treatment with pronase (DAKO) $0.05 \%$ in phosphate-buffered saline (PBS) for $5 \mathrm{~min}$ at room temperature was applied before the immunostaining for S-100. The immunostaining of all antisera, either monoclonal or polyclonal, was preceded by steps with $0.1 \%$ $\mathrm{H}_{2} \mathrm{O}_{2}$ in methanol to block the intrinsic peroxidase activity and with normal sheep serum to prevent aspecific adherence of serum proteins; the incubation was carried out at $4^{\circ} \mathrm{C}$ for $16 \mathrm{hrs}$ in a moist chamber. Finally, the biotin-streptavidin-peroxidase method (LSAB2 System-HRP multilink universal kit from DAKO) was applied. To develop the reaction, sections were incubated in darkness for 
10 min. with $3-3^{\prime}$ diaminobenzidine tetrahydrochloride (DAB) (Sigma Chemical Co., St. Louis, MO, USA), in the amount of $100 \mathrm{mg}$ in 200 $\mathrm{ml} 0.03 \%$ hydrogen peroxide in PBS. The nuclear counterstaining was performed by Mayer's haemalum for 5 min at room temperature; then slides were dehydrated in ascending ethanols, clarified in xylene and mounted with a synthetic medium (Permount). Negative controls included omission of the primary antiserum or replacement of the primary antiserum with normal horse/goat serum. In each of these conditions, no staining was evident. Placental fragments at the third trimester of pregnancy were utilized as positive control tissue for $\mathrm{CRH}$ and POMC antisera. An evident reactivity for POMC and CRF was encountered in syncytio-cytotrofoblast cellular layers of placental tissue.

Immunohistochemical localization of all somatostatin receptors (SSTRs) subtypes was performed on $5 \mu \mathrm{m}$ paraffin-embedded parallel sections with the polyclonal antibodies against

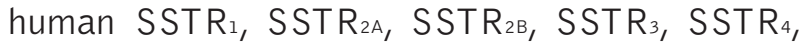
$\mathrm{SSTR}_{5}$ (all from Biotrend, Cologne, Germany; wd: 1:3500). In brief, the sections were pre-treated in microwave owen in $10 \mathrm{mM}$ citric acid, $\mathrm{pH} 6.0$ (3 cycles for $15 \mathrm{~min}$ at $100^{\circ} \mathrm{C}$ ), and incubated over night (o.n.) at $4^{\circ} \mathrm{C}$ with each antibody. A standard streptavidin-biotin-peroxidase (LSAB 2 SystemHRP multilink universal kit from DAKO) was used according to the manufacturer's instructions to visualize the bound antibodies, and the reaction was developed in DAB. Negative controls for immunochemistry included: 1) omission of the primary antibody and 2) pre-absorption of the antibodies with the respective immunizing receptor peptide. Peptide fragments of human SSTRs sub-

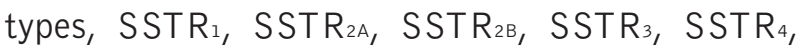
$\mathrm{SSTR}_{5}$ C-term (all from Biotrend, Cologne, Germany), were used at a concentration of 100 $\mathrm{nM}$, and incubated o.n. at $4^{\circ} \mathrm{C}$. A tissue was considered positive when the immunostaining was abolished by pre-absorption of the antibody with the respective peptide antigen. Pancreatic tissue sections were utilized as positive controls for SSTRs subtypes antisera.

\section{Results}

\section{Histological examination}

A $7.8 \times 4.8 \times 5.0 \mathrm{~cm}$ adrenal mass with a smooth grey-yellowish appearance was excised. The cut surface showed foci of necrosis and haemorrhage as well as areas of cystic degeneration, with a not uniform consistency. The tumour tissue was arranged in sheets, cords or alveolar structures constituted by neoplastic elements showing round vesicular nuclei, occasionally pleomorphic, and a granular, pale eosinophilic, cytoplasm (Figure 2
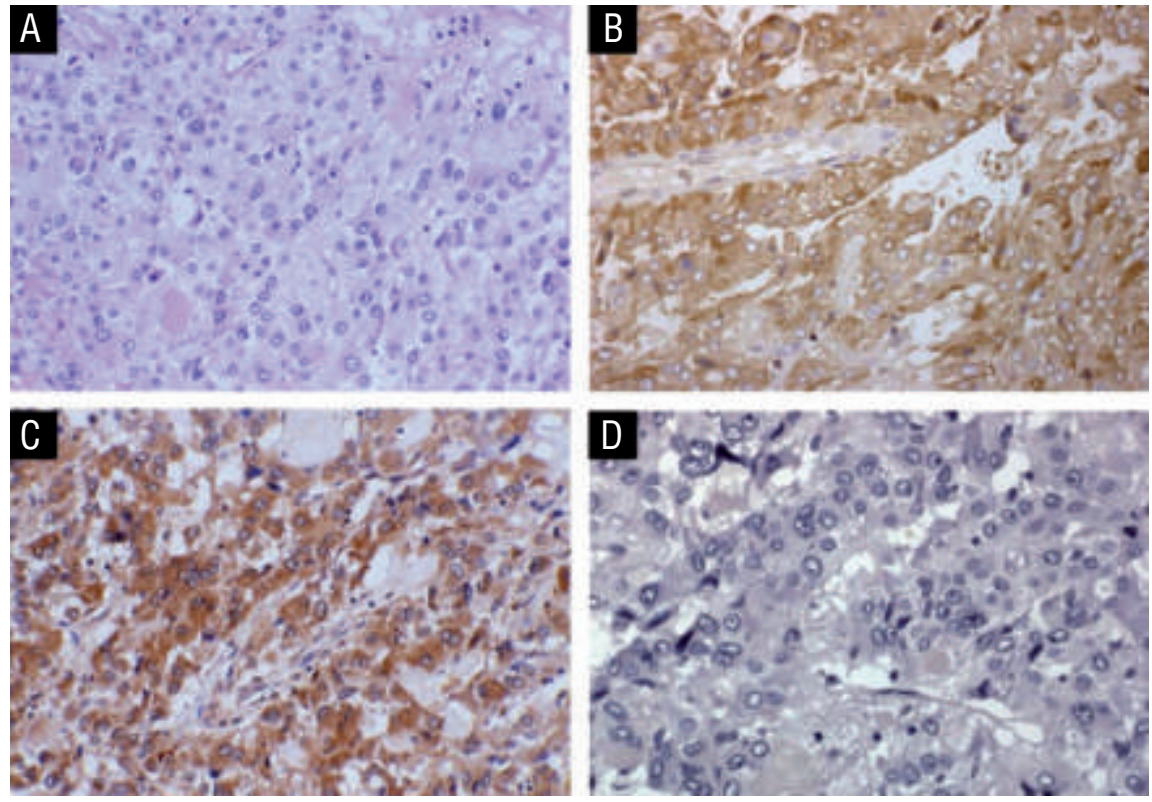

Figure 2. Histological and immunohistochemical analysis of paraffin-embedded sections from our phaeochromocytoma. (A) Haematoxylin-eosin stain. (B) intense and diffuse cytoplasmic immunoreactivity for CRH. (C) negative staining with ACTH antiserum. (D) intense chromogranin A immunoreactivity. The sections were developed with 3,3'-diaminobenzidine and counterstained with haematoxylin (magnification, 300X). 
A), in accordance with the diagnosis of pheocromocytoma. Mitoses were rare and the MIB-1 immunostaining was evident in less than $5 \%$ of neoplastic cells. There was no diffuse growth pattern, cellular atypical mitotic figures, or other signs of malignancy.

\section{Immunohistochemical characterization}

Heterogeneous intensity of positive staining was appreciable with anti-chromogranin A (Figure 2 B) and anti-neurofilaments, neuroendocrine tumour markers that are typically expressed by PHEO. A weak, occasional cytoplasmic immunopositivity was observed also with S-100 antiserum. An intense, mainly diffuse and homogeneous, cytoplasmic immunoreactivity for $\mathrm{CRH}$ was found in the tumour, with a high percentage of stained cells $(>70 \%$ )(Figure $2 \mathrm{C}$ ), thus indicating unequivocally that adrenal hyperactivity was $\mathrm{CRH}$ dependent, provided that, in contrast with increased serum ACTH levels, no immunostaining for this hormone was apparent (Figure 2 D). Only a weak immuoreactivity for the ACTH precursor POMC was found but concerned a low percentage of cells $(<30 \%)$ and was not uniform, positive cells being in contact with less reactive or negative ones. The immunohistochemical evaluation of SSTRs expression revealed a positive reaction for SSTR $R_{1}, S_{S T R}{ }_{2 A}, S S T R_{2 B}$, on tumour cells (Figure 3). The immunostaining was granular or diffuse, located in the cytoplasm of the neoplastic elements, and the intensity of the reaction was moderate to strong. A membranous staining was also present for the SSTR $\mathrm{R}_{2 \mathrm{a}}$ subtype (Figure $3 \mathrm{~B}$ ). In all cases, immunostaining could be completely abolished by pre-absorption with $100 \mathrm{nM}$ of the respective peptide antigens. The other SSTR subtypes were unreactive.

\section{Discussion}

The immunohistochemical expression of SSTR and SSTR $R_{2 a}$ and SSTR $R_{2 b}$ subtypes in the tumour cells demonstrated in the tumour of the studied patient, is correlated with clinical and functional imaging data ([111 In-DTPA $\left.{ }^{0}\right]$ octreotide scintigraphy) along with the effect of somatostin analogue treatment and the outcome of the disease.

SSTRs is a known characteristic of phaeochromocytomas (De Herder and Hofland, 2004), but

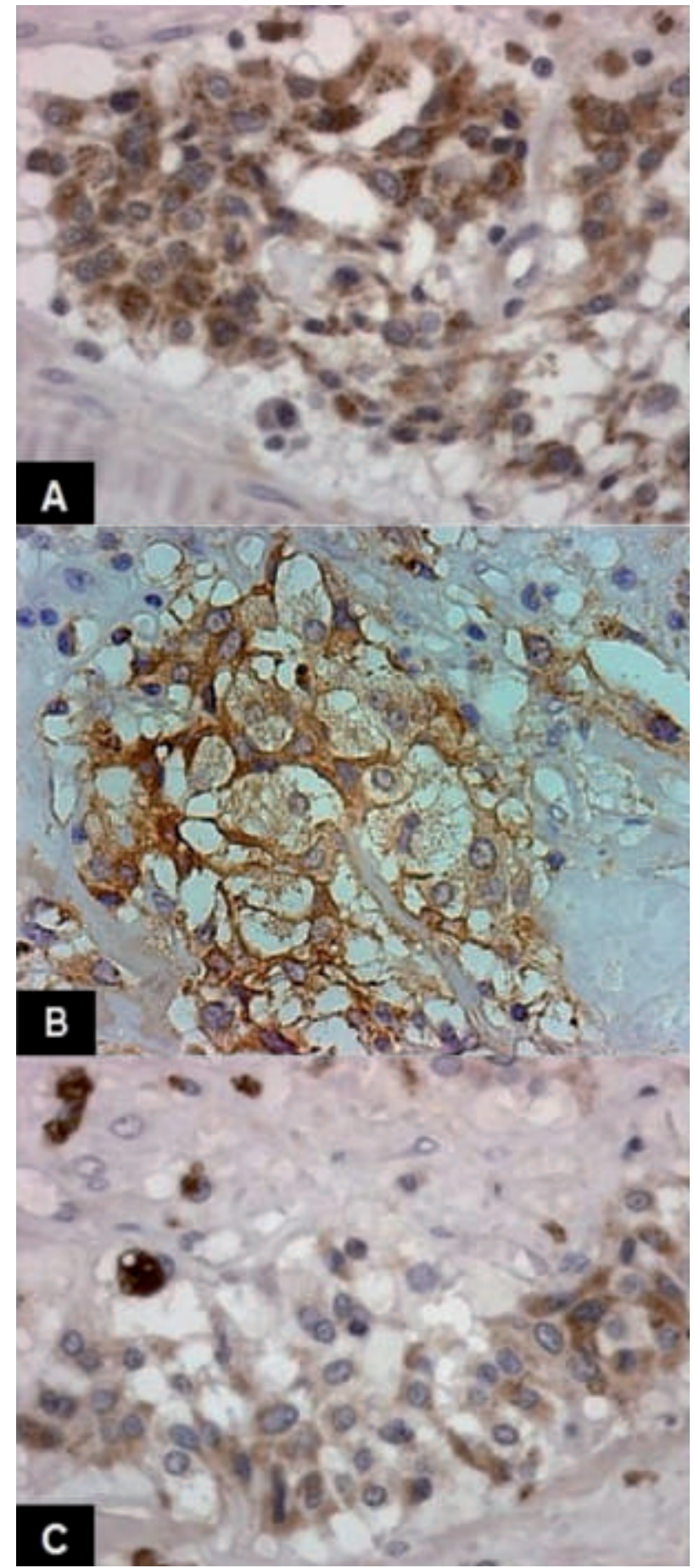

Figure 3. Positive immunostaining for $\operatorname{SSTR}_{1}$ (panel A), SSTR (panel B) and SSTR ${ }_{2 B}$ (panel C) antisera. Note the membranous immunostaining for the SSTR $\mathbf{2}_{2}$ subtype on tumour cells. The sections were developed with $3,3^{\prime}$-diaminobenzidine and counterstained with haematoxylin (magnification, 300X).

information on the specific SSTRs subtypes determination is lacking. Up to date, few data on the expression of SSTRs subtypes are available in the 
literature (Reubi et al., 1992; Kubota et al., 1994; Epelbaum et al., 1995; Hofland et al., 1999; Mundschenk et al., 2003; Unger et al., 2004; Ueberberg et al., 2005; Unger et al., 2008).

Reubi et al. (1992) for the first time demonstrated the presence of specific somatostatin receptors in phaeochromocytomas. They examined the tumour tissue with regard to the distribution of SSTR $R_{2 A}$ receptors, and found that 16 of the 18 paraffin-embedded phaeochromocytomas were stained positive for this SSTR subtype (Reubi et al., 1992). Kubota and co-workers (1994) detected SSTR 1 and SSTR ${ }_{2}$ mRNAs in three cases of phaeochromocytoma, showing an expression pattern identical to that of normal adrenal gland. Similar results were obtained by Hofland et al. (1999), who found four of five phaeochromocytomas positive for sstl and three of five positive for SSTR 2A.

Although the mentioned studies demonstrated only the expression of SSTR 1 and SSTR Authors investigated the expression pattern of all five SSTRs subtypes in benign and malignant phaeochromocytomas. The over-expression of more than one SSTR subtype (other than the sst $_{2}$ ), such as SSTR ${ }_{1}, S_{S T R}, S_{3} S_{R_{4}}$, and/or sst receptor subtypes was identified with a prevalence higher than that of SSTR2 which were found in less than $50 \%$ of these tumours (Epelbaum et al., 1995; Mundschenk et al., 2003; Unger et al., 2004; Unger et al., 2008). Epelbaum and coworkers (Epelbaum et al., 1995) demonstrated in 34 both benign and malignant phaeochromocytomas that mRNAs of all five SSTR subtypes were measurable in the tumour cells as well as in normal adrenal tissue, the SSTR 2 and SSTR $\mathrm{R}_{4}$ being the most expressed. Indeed, the vast majority (up to $90 \%$ ) of the phaeochromocytomas examined by Mundschenk and Unger showed positive immunohistochemical staining for $\mathrm{SSTR}_{3}$, in a high percent $(>60 \%)$ of tumour cells. Immunoreaction for $S S T R_{1}, S S T R_{2 a}$, and $S S T R_{5}$ receptors was found in only few tumours and with a lower expression within each tumour. Particularly, SSTR 2 expression was seen in less than $30 \%$ of phaeochromocytomas (Mundschenk et al., 2003; Unger et al., 2004; Unger et al., 2007). These observations were partially confirmed by Ueberberg et al. (2005), who investigated the expression of the five SSTRs in various adrenal tumours and in normal adrenal gland by RT-PCR. They found that each receptor subtype was expressed in normal adrenal gland and in more than $50 \%$ of all pheochromocytomas analyzed, with the SSTR $\mathrm{R}_{1}$ being present in nearly all them.

Taken together, these data demonstrate that SSTR subtypes are expressed in pheochromocytomas with tumor-specific distribution patterns, and the functional responses to somatostatin analogues depend on a mixed population of receptor. Unlike classic neuroendocrine tumors, particularly gastroenteropancreatic tumors, charactherized by SSTR2 over-expression, phaeochromocytoma may over-express other receptor subtypes, such as $\mathrm{SSTR}_{3}$ or SSTR $\mathrm{R}_{1}$ or SSTR $\mathrm{R}_{4}$, for which conventional somatostatin analogs have lower affinity. For this reason, octreotide treatment induced symptomatic or hormonal improvements only in few cases (Invitti et al., 1993; Plouin et al.,1995; Kopf et al., 1997; Lamarre-Cliche et al. 2000), suggesting that octreotide is of limited value for the treatment of this defined group of patients. It may be speculated, that other somatostatin analogues - such as pasireotide/SOM230, which has a broder spectrum than octreotide - may appear to be more efficient. Indeed, in vitro studies have shown inhibition of cell proliferation, induction of apoptosis and reduction of catecholamine secretion (Pasquali et al., 2008), but clinical studies are necessary to confirm these effects.

Nevertheless, a number of pheochromocytomas express the SSTR $\mathrm{R}_{2}$ receptor and are able to uptake the radiotracer during octreotide scintigraphy, representing potential target of treatment with somatostatin analogs. In our patient, the SST analog octeotide was able to control hormone hyper secretion and to improve the patient's general condition. The effectiveness of octreotide treatment was related to the expression of SSTR receptors (mainly the SSTR 2 subtype), as preoperatively suggested by an octreoscan performed before starting therapy and demonstrated postsurgically by immunohistochemistry.

Our report confirms the heterogeneity of the pattern of SSTR expression in pheochromocytomas, and provide further evidence for expression of functional SSTR subtype SSTR 2 in a subgroup of pheochromocytomas. The SST analog octreotide can effectively control symptoms resulting from excessive hormone release and may be performed to achieve a rapid control of the dis- 
ease before surgery in such patients. Diagnostic imaging with the $\left.{ }^{[11} \mathrm{In}_{\mathrm{DTTPA}}{ }^{0}\right]$ octreotide scan can demonstrate the presence of this specific receptor subtype on these tumours and may help to identify those patients who will have a response to octreotide therapy.

Finally, in our patient, who represent an unprecedented clinical case, the $\mathrm{CRH}$ production by the phaeochromocytoma was revealed by the immunohistochemical analysis, that demonstrated a very strong staining for $\mathrm{CRH}$ in the tumour cells, in the complete absence of ACTH staining. The $\mathrm{CRH}$ secretion by the tumour induced pituitary hyperfunction, as demonstrated by the promptly post-surgical recovery of hypothalamic-pituitaryadrenal axis activity, which made unnecessary steroid replacement after adrenalectomy.

\section{References}

Bayraktar F, Kebapcilar L, Kocdor MA, Asa SL, Yesil S, Canda S, et al. Cushing's syndrome due to ectopic $\mathrm{CRH}$-secretion by adrenal phaeochromocytoma accompanied by renal infarction. Exp Clin Endocrinol Diabetes 2006;114:444-7.

Chen H, Doppman JL, Chrousos GP, Norton JA, Nieman LK, Udelsman R. Adrenocorticotropic hormone-secreting phaeochromocytomas: the exception to the rule. Surgery 1995; 118: 988-95.

de Herder WW and Hofland LJ. Somatostatin receptors in pheochromocytoma. Front Horm Res 2004;31: 145-54.

Eng PH, Tan LH, Wong KS, Cheng CW, Fok AC, Khoo DH. Cushing's syndrome in a patient with a corticotropin-releasing hormone-producing phaeochromocytoma. Endocr Pract 1999;5: 84-7.

Epelbaum J, Bertherat J, Prevost G, Kordon C, Meyerhof W, Wulfsen I, et al. (1995). Molecular and pharmacological characterization of somatostatin receptor subtypes in adrenal, extraadrenal, and malignant pheochromocytomas. J Clin Endocrinol Metab 1995;80: 1837-44.

Hofland LJ, Liu Q, van Koetsveld PM, Zuiderwijk J, van der Ham F, de Krijger RR, et al. Immunhistochemical detection of somatostatin receptor subtypes sstl and sst2A in human somatostatin receptor positive tumors. J Clin Endocrinol Metab 1999;84:775-80.

Invitti C, De Martin I, Bolla GB, Pecori Giraldi F, Maestri E, Leonetti $G$, et al. Effect of octreotide on catecholamine plasma levels in patients with chromaffin cell tumors. Horm Res 1993;40:156-60.
Kopf D, Bockisch A, Steinert H, Hahn K, Beyer J, Neumann HP, et al. Octreotide scintigraphy and catecholamine response to an octreotide challenge in malignant phaeochromocytoma. Clin Endocrinol (Oxf) 1997; 46:39-44.

Kubota A, Yamada Y, Kagimoto S, Shimatsu A, Imamura M, Tsuda K, et al. Identification of somatostatin receptor subtypes and an implication for the efficacy of somatostatin analogue SMS 201-995 in treatment of human endocrine tumors. J Clin Invest 1994;93: 1321-5.

Lamarre-Cliche M, Gimenez-Roqueplo AP, Billaud E, Baudin E, Luton $J P$, Plouin PF. Effects of slow-release octreotide on urinary metanephrine excretion and plasma chromogranin A and catecholamine levels in patients with malignant or recurrent phaeochromocytoma. Clin Endocrinol (Oxf) 2002;57:629-34.

Mundschenk J, Unger N, Schulz S, Höllt V, Schulz S, Steinke R, et al. Somatostatin receptor subtypes in human pheochromocytoma: subcellular expression pattern and functional relevance for octreotide scintigraphy. J Clin Endocrinol Metab 2003;88:5150-57.

O'Brien T, Young WF, Davila DG, Scheithauer BW, Kovacs K, Horvath $E$, et al. Cushing's syndrome associated with ectopic production of corticotropin-releasing hormone, corticotropin and vasopressin by a phaeochromocytoma. Clin Endocrinol (Oxf) 1992;37:460-7.

Pacak K, Linehan WM, Eisenhofer G, Walther MM, Goldstein DS. Recent advances in genetics, diagnostic, localization and treatment of phaeochromocytomas. Ann Intern Med 2001;134:315-29.

Pasquali D, Rossi V, Conzo G, Pannone G, Bufo P, De Bellis A, et al. Effects of somatostatin analog SOM230 on cell proliferation, apoptosis, and catecholamine levels in cultured pheochromocytoma cells. $\mathrm{J}$ Mol Endocrinol 2008;40:263-71.

Plouin PF, Bertherat J, Chatellier G, Billaud E, Azizi M, Grouzmann E et al. Short-term effects of octreotide on blood pressure and plasma catecholamines and neuropeptide $Y$ levels in patients with phaeochromocytoma: a placebo-controlled trial. Clin Endocrinol (Oxf) 1995;42:289-94.

Reubi JC, Waser B, Khosla S, Kvols L, Goellner JR, Krenning E et al. In vitro and in vivo detection of somatostatin receptors in pheochromocytoma and paraganglioma. J Clin Endocrinol Metab 1992;74: 1082-9.

Ueberberg B, Tourne H, Redman A, Walz MK, Schmid KW, Mann K, et al. Differential expression of the human somatostatin receptor subtypes sstl to sst5 in various adrenal tumors and normal adrenal gland. Horm Metab Res 2005;37:722-8.

Unger N, Serdiuk I, Sheu SY, Walz MK, Schulz S, Schmid KW et al. Immunoistochemical determination of somatostatin receptor subtypes 1, 2a, 3, 4 and 5 in various adrenal tumours. Endocrine Res 2004;30:931-4.

Unger N, Serdiuk I, Sheu SY, Walz MK, Schulz S, Saeger W, et al. Immunohistochemical localization of somatostatin receptor subtypes in benign and malignant adrenal tumors. Clin Endocrinol (Oxf) 2008; 68:850-7.

White A, Ray DW, Talbot A, Abraham P, Thody AJ, Bevan JS. Cushing's syndrome due to phaeochromocytoma secreting the precursors of adrenocorticotropin. J Clin Endocrinol Metab 2000;85: 4771-5. 